\title{
Acidosis after Laparoscopic Inguinal Hernia Repair: Report of a Case
}

\author{
${ }^{1}$ Yusuf Sevim, ${ }^{2}$ Ali Can Yali, ${ }^{3}$ Talha Sarigoz, ${ }^{4}$ Omer Topuz, ${ }^{5}$ Tamer Ertan \\ ${ }^{1}$ MD, FTBS, Ankara Numune Training and Research Hospital, Department of General Surgery, \\ Division of Colorectal Surgery, Ankara, Turkey \\ ${ }^{2,3} \mathrm{MD}$, Kayseri Training and Research Hospital, Department of General Surgery, Kayseri, Turkey \\ ${ }^{4,5}$ Assoc Prof, Kayseri Training and Research Hospital, Department of General Surgery, Kayseri, \\ Turkey \\ yusufsevim@gmail.com,alicanyali01@gmail.com,dr.talhasarigoz@yahoo.com, \\ drotopuz@yahoo.com,tertan70@hotmail.com
}

Running Head: Acidosis following laparoscopic herniorrhaphy

\begin{abstract}
Groin hernias are among the most common of all surgical problems, and should be managed laparoscopically. The most commonly performed laparoscopic herniorrhaphy techniques are totally extraperitoneal and transabdominal preperitoneal repair. These procedures may affect respiratory and cardiovascular functions. Respiratory acidosis is a rare complication of laparoscopic hernia repair because of the absorption of $\mathrm{CO}_{2}$ through capillary vessel or peritoneum. Here we report the rare complication, respiratory acidosis, following laparoscopic extraperitoneal hernia repair. Acidosis was recovered with regulation of mechanic ventilation by increasing respiratory rate and end-tidal volume, and an overventilation before tracheal extubation. Clinicians should be aware of respiratory acidosis during laparoscopic hernia repair and its management beside cardiovascular and respiratory effects.
\end{abstract}

Keywords: Acidosis; Herniorrhaphy; Laparoscopy.

\section{INTRODUCTION}

Repair of inguinal hernia is one of the most common surgical procedure performed in the world (1). Laparoscopic inguinal hernia repair was introduced in the early 1990s (2-4). Reduced postoperative pain, diminished requirement for narcotics, and earlier return to work are the advantages of laparoscopic inguinal hernia repair over conventional open repair (5-7). The most commonly performed laparoscopic herniorrhaphy techniques are totally extraperitoneal (TEP), and transabdominal preperitoneal (TAPP) repair. Postoperative complications are possible with laparoscopy, as with any other hernia repair. Seroma and hematoma formations are relatively common minor complications of inguinal hernia repair and more significant complications are postoperative pain, post- herniorrhaphy neuralgia, and hernia recurrence. The absorption of $\mathrm{CO}_{2}$ through capillary vessel or peritoneum accumulates to gradually results in acidosis, and this is a rare complication (8). Here, we want to report our laparoscopically treated case with inguinal hernia complicated as postoperative acidosis.

\section{CASE}

The 53-year-old male patient admitted to our clinic with swelling and pain in the groin. He was using calcium channel canal blocker, amlodipine, atorvastatin, and acetylsalicylic acid for coronary artery disease and hypertension. The patient was prepared to laparoscopic management, and acetylsalicylic acid discontinued 3 days before the operation. Laparoscopic extraperitoneal inguinal hernia repair was performed. Acidosis was detected by arterial blood gases analysis ( $\mathrm{pH}: 7.259, \mathrm{pCO}_{2}: 46.1, \mathrm{HCO}^{3-}$ : $20 \mathrm{mmol}$, BE: -6,7). Acidosis was recovered with regulation of mechanic ventilation by increasing respiratory rate and end-tidal volume, and an overventilation before tracheal extubation. There were no other additional complications and the patient was discharged on postoperative $2^{\text {nd }}$ day. 


\section{DisCUSSION}

Acidosis following laparoscopic managements is a rare complication, and $\mathrm{CO}_{2}$ pneumoperitoneum is accused in pathophysiology of the situation. Insufflations of $\mathrm{CO}_{2}$ in laparoscopic surgeries may affect cardiovascular and pulmonary function of the patients that higher blood pressure and slower heart rate occurred clinically. The absorption of $\mathrm{CO}_{2}$ through peritoneum and capillary vessels results in acidosis because of accumulation of $\mathrm{CO}_{2}$ gradually. $\mathrm{Zhu}$ and colleagues studied TAPP and TEP procedures, and they determined increase of end-tidal $\mathrm{CO}_{2}, \mathrm{PaCO}_{2}$, and $\mathrm{HCO}^{-3}$, decrease of $\mathrm{pH}$ value, and fluctuation of heart rate and blood pressure, and also the authors mentioned prolonged surgeries aggravated these variations (8). Accumulation of $\mathrm{CO}_{2}$ may cope with suitable regulation of mechanical regulation of mechanic ventilation by increasing respiratory rate and end-tidal volume, and an overventilation before tracheal extubation. In our case, we performed these mechanical arrangements for acidosis, and the acidosis relieved.

Iatrogenic respiratory acidosis during laparoscopic preperitoneal hernia repair was published in 1996, and the authors thought that the acidosis occurred because of undefined borders and the preperitoneal space was particularly vulnerable to massive subcutaneous emphysema formation (9). Before this, another study compared the duration of development of hypercarbia between laparoscopic hernia repair and laparoscopic cholecystectomy. Liem et al. mentioned that more rapid increase in $\mathrm{PaCO}_{2}$, consequent decrease in $\mathrm{pH}$ was found in laparoscopic herniorrhaphy compared to laparoscopic cholecystectomy. Also, they mentioned the maximum observed value for $\mathrm{PaCO}_{2}$ and the minimum observed values for $\mathrm{pH}$ were not statistically significant during the two procedures (10).

\section{Conclusion}

Although TEP procedure better protects peritoneum with less abdominal complications, respiratory acidosis may occur. Anesthesiologists and surgeons should be aware of this complication, and its management beside cardiovascular and respiratory effects.

\section{ACKNOWLEDGEMENTS}

The authors thank Duygu Gulmez Sevim, MD, for her assistance in writing of this article.

\section{REFERENCES}

[1] Jenkins JT, O'Dwyer PJ. Inguinal hernias. Bmj. 2008;336(7638):269-272.

[2] Schultz L, Graber J, Pietrafitta J, Hickok D. Laser laparoscopic herniorraphy: a clinical trial preliminary results. J Laparoendosc Surg. 1990;1(1):41-45.

[3] Schultz LS, Graber JN, Pietrafitta J, Hickok DF. Early results with laparoscopic inguinal herniorrhaphy are promising. Clinical laser monthly. 1990;8(7):103-105.

[4] Blamey SL, Wale RJ. Laparoscopic repair of inguinal hernia. The Medical journal of Australia. 1991;155(10):718.

[5] Kark AE, Kurzer MN, Belsham PA. Three thousand one hundred seventy-five primary inguinal hernia repairs: advantages of ambulatory open mesh repair using local anesthesia. J Am Coll Surg. 1998;186(4):447-455; discussion 456.

[6] Novitsky YW, Czerniach DR, Kercher KW, Kaban GK, Gallagher KA, Kelly JJ, et al. Advantages of laparoscopic transabdominal preperitoneal herniorrhaphy in the evaluation and management of inguinal hernias. Am J Surg. 2007;193(4):466-470.

[7] Memon MA, Cooper NJ, Memon B, Memon MI, Abrams KR. Meta-analysis of randomized clinical trials comparing open and laparoscopic inguinal hernia repair. $\mathrm{Br} \mathrm{J}$ Surg. 2003;90(12):1479-1492.

[8] Zhu Q, Mao Z, Yu B, Jin J, Zheng M, Li J. Effects of persistent CO(2) insufflation during different laparoscopic inguinal hernioplasty: a prospective, randomized, controlled study. J Laparoendosc Adv Surg Tech A. 2009;19(5):611-614.

[9] Waisbren SJ, Herz BL, Ducheine Y, Yang HK, Karanfilian RG. Iatrogenic "respiratory acidosis" during laparoscopic preperitoneal hernia repair. J Laparoendosc Surg. 1996;6(3):181-183.

[10] Liem MS, Kallewaard JW, de Smet AM, van Vroonhoven TJ. Does hypercarbia develop faster during laparoscopic herniorrhaphy than during laparoscopic cholecystectomy? Assessment with continuous blood gas monitoring. Anesth Analg. 1995;81(6):1243-1249. 